\title{
Research is needed to assess the unique nutrition and wellness needs of aging Californians
}

\author{
by Mary L. Blackburn, Barbara Gillogy, and \\ Peggy Hauselt
}

\section{Inadequate diet and nutrition can} contribute to or exacerbate chronic and acute diseases, hasten the development of degenerative diseases associated with aging, and delay recovery from illness. No single segment of society can benefit more from improved diet and nutrition, and regular exercise, than the elderly. While links between diet, exercise and chronic-disease risks are well documented, more research is needed on how best to use quality-of-life approaches and perceived benefits as motivators for behavior change among the elderly. This report explores how physiological components affect the nutrition and wellness of seniors, puts into context the status of related research, and helps establish a framework to reassess UC Cooperative Extension priorities for applied research, education and outreach to California's elderly population.

$\mathrm{M}$ ore than 50 years ago, the World Health Organization redefined health as more than merely the absence of disease, expanding it to include the physical, mental and social well-being of populations (Damron-Rodriquez et al. 2005). One of the goals of the National Guidelines for Health Promotion and Disease Prevention (the "Healthy People 2010" report published in January 2000 by the U.S. Department of Health and Human Services) was to "extend the years of 'healthy life' in a physical, mental and social context" (US DHHS 2000).

The number of older Americans is projected to double by 2030, and one in

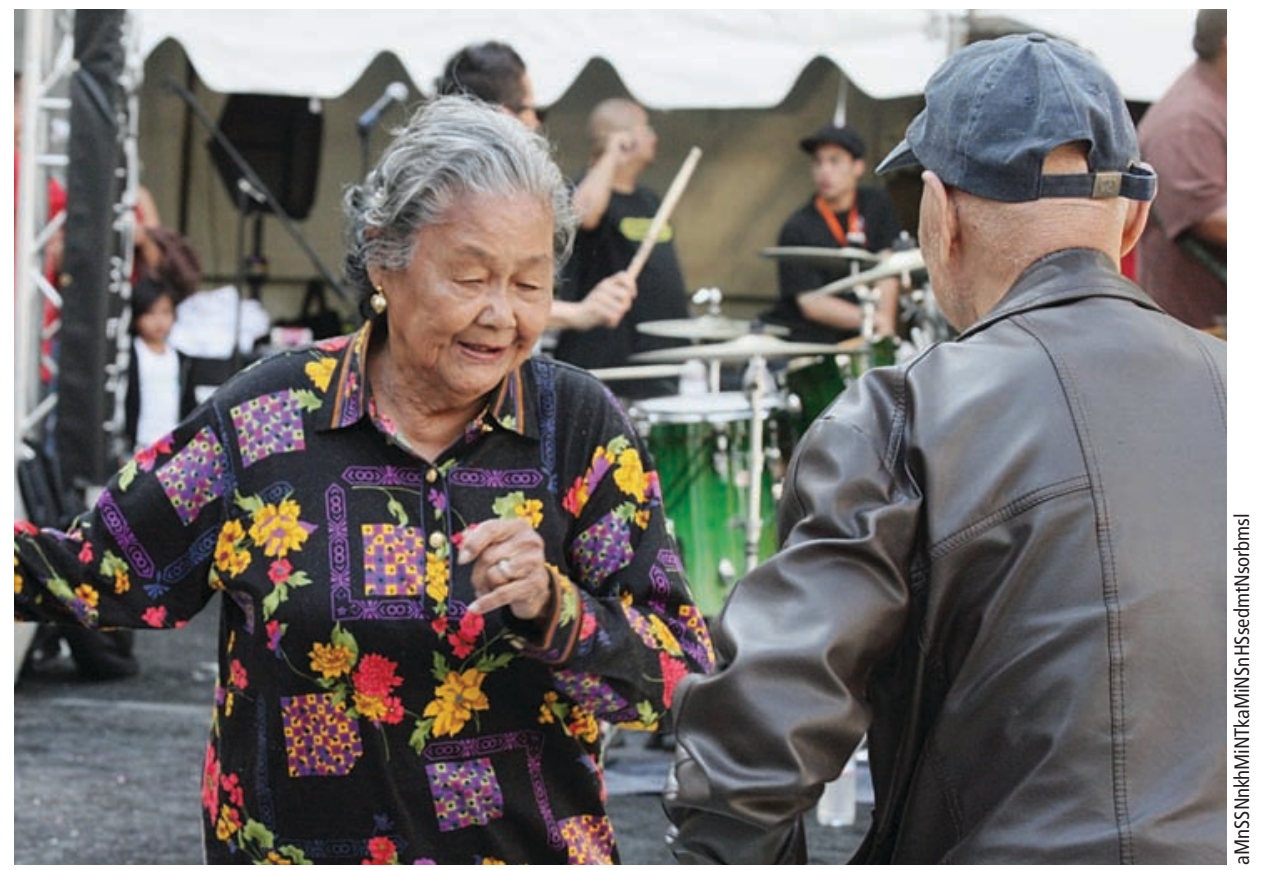

A public health approach to aging would promote the conditions under which people can be healthy, with emphasis on increasing wellness rather than preventing disease.

nine baby boomers is expected to live until age 90 . This will place tremendous demands on retirement income, and health and social services. The rapid expansion of the population 65 years and older has already had an economic impact on health-care budgets at all levels. The greatest use of the health-care system occurs during the last years of life (Chernoff 2001), and health experts have projected that at least 7 years of one's life will be spent in ill health (Economist 2000). The health-care expenditures of those over 65, who make up about $13 \%$ of the U.S. population, account for at least 30\% of the nation's annual health-care costs. Hospital use by people over 65 is about three times that of younger people, and individuals in this group fill the majority of beds in skilled-care facilities (Weimer 1998).

The Institute of Medicine (2002) has called for a public health approach to promote the conditions under which people can be healthy, emphasizing health rather than disease, being proactive rather than reactive, and focusing on populations rather than individuals (Wallace 2005).
This report puts into context the status of research and development on the nutrition and wellness needs of aging Americans, particularly in California. It helps establish a framework in which UC Cooperative Extension (UCCE) priorities for applied research, and nutrition and wellness education for the elderly, can be reassessed. We used data from the 2001 U.S. Census and the 2001 California Health Interview Survey (CHIS) (Wallace et al. 2003) to show the status of major chronic-disease conditions among older Californians. We also conducted a literature review of scientific research on how physiological factors contribute to the nutrition and wellness status of seniors.

\section{Healthy aging becomes a necessity}

The percentage of elders in California is growing faster than the rest of the country (Aldwin and Gilmer 2001). California's population of seniors 65 and over is about 4.1 million, or $11.2 \%$ of the total population, and county proportions vary (US Census Bureau 2010). The ethnic composition of seniors 65 and older is about 16\% white, $10 \%$ 
Asian/Pacific Islander, 8\% black, 7\% American Indian, and 4\% Latino (Lopez 2002).

Between 1990 and 2020, more than half of California counties were expected to double their proportion of seniors 65 and over (AOA 2003). Seniors 85 years and older will increase at the highest rate, more than $150 \%$ in 38 of California's 58 counties. The significance and impact of this oldest group will become more evident between 2030 and 2040, when the first wave of baby boomers reaches age 85 (CDA 2003).

This demographic shift has thrust health and quality-of-life issues during the oldest years into the public eye. With one in four families currently caring for a family member, the Institute of Medicine (2008) reported that some feel older people are unproductive, cost too much and cause intergenerational conflict. Health-care and other costs have forced aging issues into the institutional consciousness of the social, educational, economic, financial and medical/ health-care systems. Promoting healthy aging is expected to become more important as the baby-boom generation places increasing demands on health care and other service systems (Albert et al. 2002).

Three important aspects of healthy aging are physical health, mental health and active engagement with life (Rowe and Kahn 1997). The goal of Healthy People 2000 was to increase the span of healthy life, but Healthy People 2010 stresses quality of life and overall well-being, along with increasing life expectancy (US DHHS 2000). Adding life to years rather than years to life is a quality-of-life concept. Biological

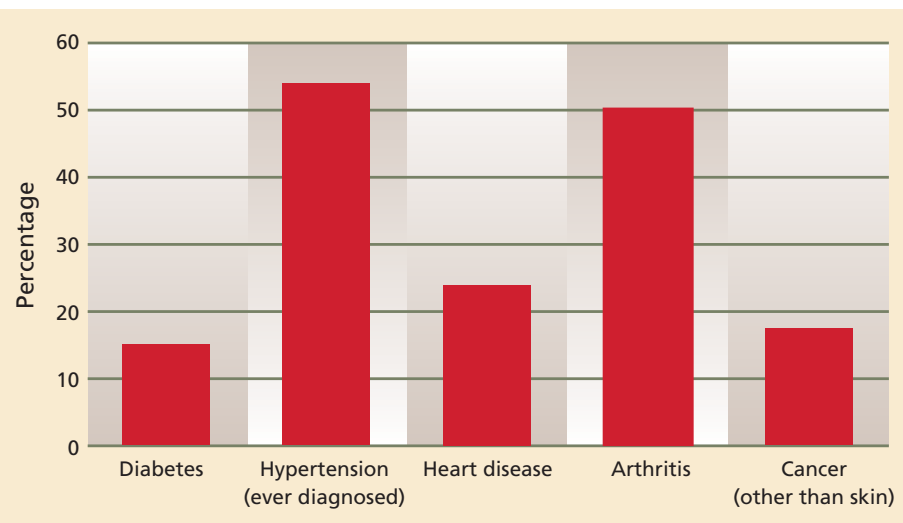

Fig. 2. Top five chronic illnesses in California, 2001. Source: Wallace et al. 2003. scientists agree that optimal nutrition and physical activity contribute to the overall quality of life at any age, especially for older adults (Hughes et al. 2005). No single segment of society can benefit more from improved diet and nutrition and regular exercise than the elderly (Drewnowski and Evans 2001).

Studies to assess the nutritional needs of elders living independently (those not in institutional settings or hospitalized) have not been a major part of mainstream research in California or the nation, and much of the early research focused on disease conditions as opposed to healthy-living indicators and promotion.

\section{Nutrition and wellness risk factors}

Several longitudinal studies now under way are examining the basis for good health in the very old, as well as the potential causes of frailty and common diseases (Ljubuncic et al. 2008). Chronic diseases that compromise their quality of life and well-being affect more than 90 million Americans. For example, obesity (a high-risk factor for diabetes) and other nutrition and lifestyle conditions are common nationwide. Based on a body mass index greater than $30 \%, 39.7 \%$ of California seniors over age 65 were overweight and 16.6\% were obese in 2003 (fig. 1).

In a national cohort study, dietary patterns were found to predict mortality (Kant et al. 2004). Inadequate diet and nutrition can contribute to or exacerbate chronic and acute diseases, hasten the development of degenerative diseases associated with aging (fig. 2),
Fig. 1. Obesity rates of California elders with body mass index (BMI) more than 30, in 2001. (Estimates are unreliable for Madera, Napa, Nevada, Plumas and Sierra counties.) Source: Wallace et al. 2003.

Obesity (\%)

$$
\text { 10-14 }
$$$$
\text { 15-18 }
$$$$
\text { - } 19-22
$$$$
\text { - 23-26 }
$$

and delay recovery from illness. While links between diet and exercise and chronic disease are well documented, more research is needed on how best to use quality-oflife approaches and perceived benefits as motivations for behavior change.

Changes in diet and activity patterns are most effective in preventing nutrition-related conditions when they are initiated early in life, but positive benefits can be achieved at any age. Nutrition, however, is not routinely integrated into the health care of older Americans, such as screenings for hypertension, cholesterol, hearing, vision, blood sugar and certain cancers (Chernoff 2001). Hypertension, which has major nutrition implications, is a risk factor for a number of other chronic diseases; prevalence rates among the elderly population in California counties range from $41 \%$ to $45 \%$, to $60 \%$ to $63 \%$ (fig. 3).

Which aspects of improved diet, nutrition and fitness contribute most to wellness and quality of life in the aging process is a crucial research question. Extrapolating values from younger adults for older adults is believed to be insufficient, as is defining adequate nutrition by the amount of particular nutrients needed to maintain blood serum levels (Saltzman and Russell 1998). 
The Dietary Guidelines for Americans, first published in 1980 as Recommended Dietary Allowances (RDAs), makes recommendations for a pattern of eating that is adaptable by the public. As updated in 2005, the guidelines acknowledge that consumers need good advice to make informed choices about diets that support longer, healthier and more active lives (US DHHS 2005a). However, there is limited science-based research delineating the nature of and quantitative requirements for healthy and active older Americans (Amarantos et al. 2001). Some biological scientists believe the Dietary Guidelines for Americans should consider the functional application of nutritional requirements for optimal aging from a health-promotion perspective.

Diverse approaches are needed for health professionals and clients to understand the causes and effects of under- and overnutrition on wellness, common diseases and frailty among the elderly. For example, adequate nutrients could be measured in terms of improvement in disease markers such as homocystine (an amino acid believed to increase the risk of heart disease at elevated concentrations), and the

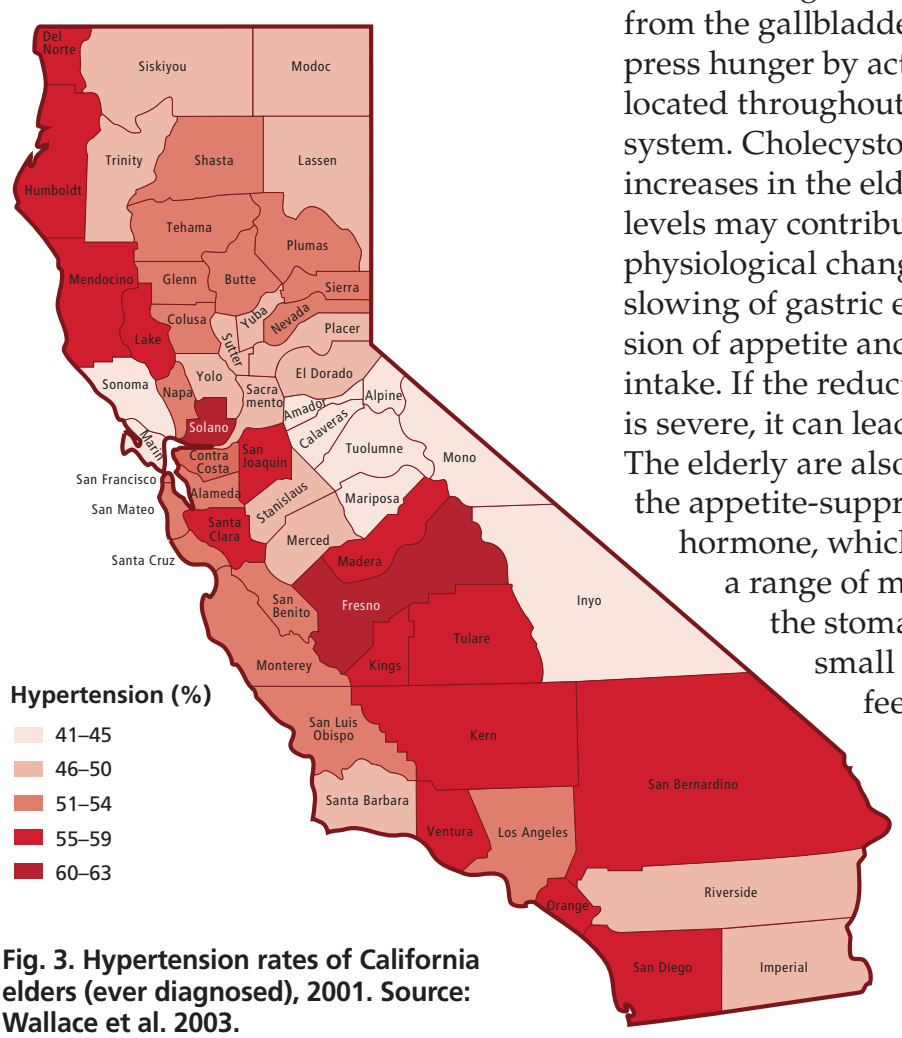

prevention of chronic diseases such as osteoporosis (Wallace 2005).

\section{Physiological changes in seniors}

Dietary intake and patterns can change with age, and there is some evidence of change in metabolic and absorptive functions. A review of cross-sectional and cohort data found a total energy decline of 1,000 to 1,200 kilocalories (kcal) among males and 600 to $800 \mathrm{kcal}$ among females (Wakimoto and Block 2001). Reduced intake of most other nutrients ranged from onefifth to one-third of established RDAs. However, the impact of these reduced intakes on the nutrition and wellness of independent-living, active, older Americans is not known.

A number of physiological reasons have been suggested for the decreased food intake observed among the aged (Morley 2001). It may be related to the adaptive relaxation of the bottom of the stomach (fundus), which occurs as we age, increasing the rate at which the stomach fills and leading to early satiation - the feeling of being full. The hormone cholecystokinin, produced in the walls of the small intestine, is secreted in the upper small intestine (duodenum). This hormone triggers the release of digestive enzymes and bile from the gallbladder, but it can also suppress hunger by acting on receptor sites located throughout the central nervous system. Cholecystokinin production increases in the elderly, and the higher levels may contribute to a number of physiological changes including the stric emptying, suppression of appetite and reduction of food intake. If the reduction of food intake is severe, it can lead to malnutrition. The elderly are also more sensitive to appetite-suppressive effects of the mone, which is believed to affect metabolic responses in mall intestine, and lead to feelings of nausea. Some mild or low-grade inflammatory disorders, and decreased activity of the hypothalamus the portion of the brain that exerts

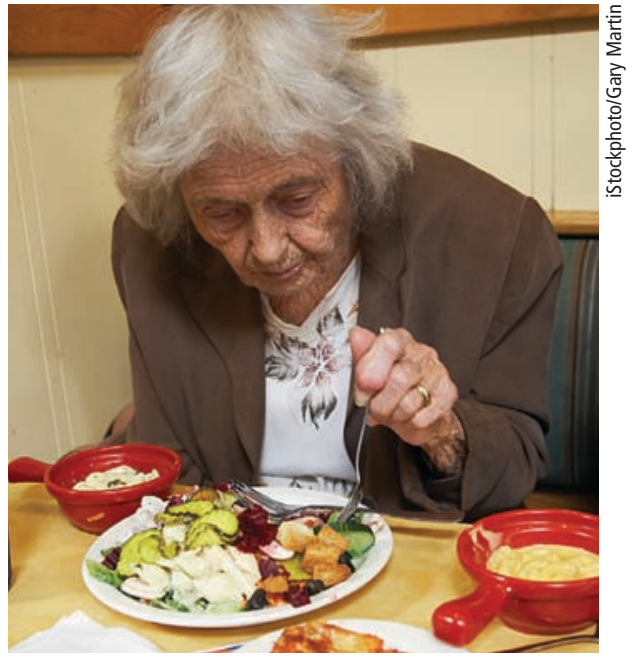

Dietary intake changes with age, perhaps due in part to physiological changes in the digestive system that make older people feel full faster.

control over visceral activities, water balance, temperature and sleep) may also result in reduced food intake. In older men, declines in the hormone testosterone and increases in the hormone leptin, which regulates hunger and energy expenditure, may also explain some of the decline in energy and food intake. Studies at UC Davis with senescent (aging) Fischer rats have documented shorter feeding times and smaller intakes, which may be suggestive of earlier satiation (Blanton et al. 1998).

In general, the small intestine undergoes few clinical and physiological changes in aging. However, about one-third of older adults suffer from an "aging gut," which can lead to a reduction or inability of the stomach to secrete gastric acid (atrophic gastritis). The lack of gastric acid can lead to an overgrowth of bacteria in the small intestine and may have an impact on the absorption of micronutrients such as iron, folate, calcium, vitamin $\mathrm{K}$ and vitamin B-12 (Saltzman and Russell 1998). Lactose intolerance (the inability to digest milk), common among about $25 \%$ of elders worldwide, can lead to a restriction in the intake of dairy products and sometimes, the development of osteoporosis.

\section{Aging and nutrient intakes}

Cellular senescence (aging) is described as the process in which normal, diploid, differentiated cells (those 


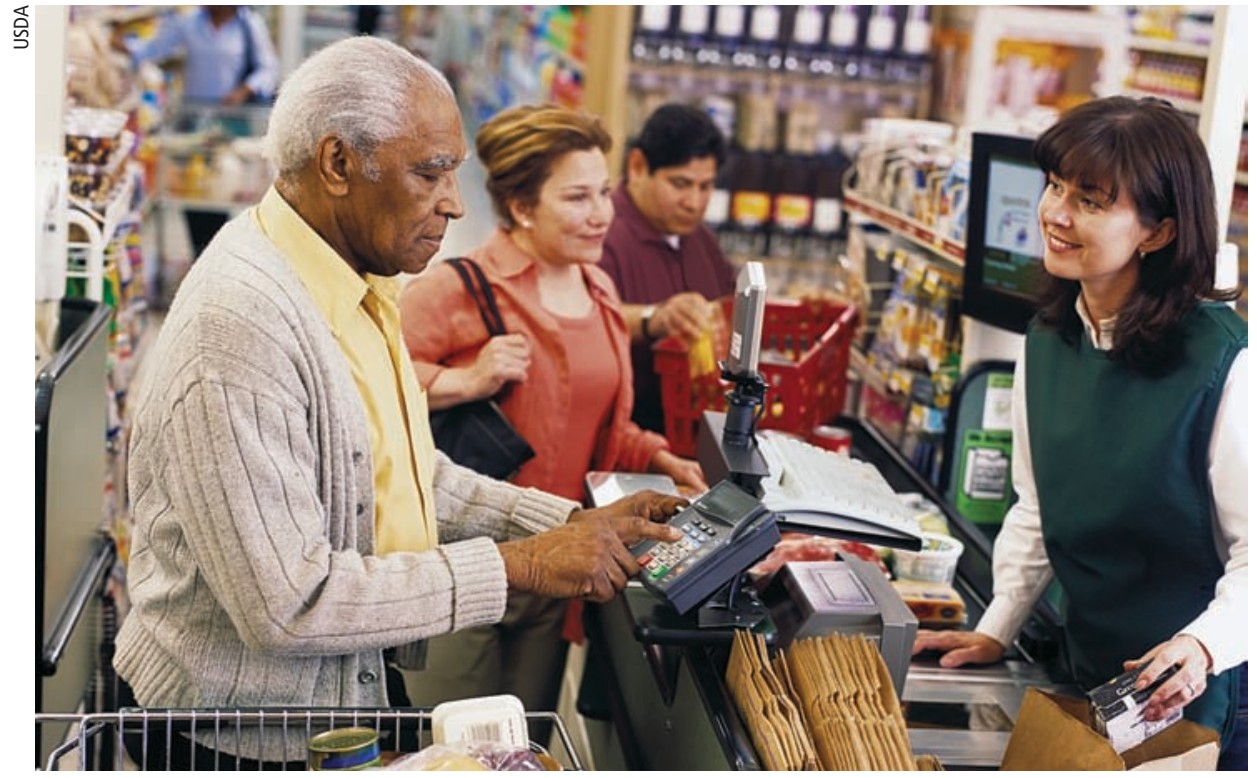

The relationship between certain nutrients and particular diseases is well established, such as iron and anemia, and calcium and osteoporosis; but the role of aging in how the body processes nutrients is not well understood.

having two sets of chromosomes) lose the ability to divide and, therefore, die. Senescence of the whole organism is characterized by a decline in the organism's ability to respond to stress, homeostatic imbalance and an increased risk of diseases associated with aging, leading ultimately to death. Genetics may affect the natural rate of aging within species as seen in mice, which are elderly at about age 3 , and some reptiles and fish, which age at a much slower rate. Life-span variation within species may be related to inherited differences in the organism's ability to slow the aging process, such as the efficiency of DNA repair, levels of antioxidant enzymes and rates of free-radical production, called the Gompertz-Makeham law of mortality (Gompertz 1860).

Among humans, however, variables such as gender, economics, poverty, environment, diet, public health and access to medical care affect the life span of populations in the United States and other countries and lead to differences between population groups. Thus, human life expectancy does not adhere to Gompertz's law of mortality after age 30 (Ekonomov et al. 1989; Pakin and Hrisanov 1984). However, life expectancy may be calculated starting with agespecific death rates and used statistically to summarize the health status of populations or groups (Lee and Carter 1992).
Historically, there are known relationships between some nutrients and disease processes, including scurvy and vitamin $C$, beriberi and vitamin $B$, vision-related disease and vitamin $\mathrm{A}$, anemia and iron, and osteoporosis and calcium. If aging/senescence is technically defined as a progressive failure of genes to maintain and repair, which leads to a reduced capacity of biological systems to function in a homodynamic fashion, how does nutrition enter into the equation? What intercellular or biochemical responses associated with the biological processes of aging cells are nutrient driven? A theory related to evolution suggests that genes that increase fitness in early life may have negative affects in later life. For example, a gene that codes for the deposit of calcium in the bones in early life may have negative affects in old age if it promotes calcium deposits in the arteries (Williams 1957).

Some research questions relevant to the broader issues of nutrition and wellness concern the impact of selected nutrients on chronic diseases of aging. For example, sucrose and dietary carbohydrates (sugars and starches) are significant because type 2 diabetes is so prevalent, occurring in about $15 \%$ of Californians over age 65 . We need to understand the role that these nutrients play in the disease's prevention, onset and management.
Basic animal research conducted at UC and other institutions has increased our understanding of cellular and whole-organism responses to selected nutrients during the onset or progression of the aging process. General research with Sprague-Dawley and Fischer rats, and in vitro studies at UC Davis, have examined a number of questions, including: rates of aging; alterations in food intake and body temperature; the interactions of dietary restriction, dietary carbohydrates and life span; the hypothalamic affect in the control of food intake during aging; and the cellular proliferation of brown adipose tissue (fat).

UC Davis researchers have published a number of relevant studies on issues such as the impact of age and diet on glucose tolerance; dietary sugars and lipid metabolism; and aging, meal patterns and reduced food intake. A clientcentered report of relevant university studies on aging is needed to present a more detailed prospectus for the UC Division of Agriculture and Natural Resources (ANR) and its constituents. UCCE could develop user-friendly education briefs and/or fact sheets for use by the general public. An important objective of the report(s) should be how these findings can be used to develop a strategic plan of applied research, educational programs and intervention strategies to address the nutrition and wellness needs of California's elders.

\section{Physical components of nutrition}

Many elders have trouble eating and accessing healthy foods. Their food choices may be partly based on factors other than nutrition knowledge (US DHHS 2005b). For example, an upset stomach may result in the avoidance of foods suspected of causing the problem, ultimately limiting the intake of fiber, vitamins, calcium and protein. Difficulty chewing may affect the consumption of meat, fresh fruits and vegetables. Food may seem to have no flavor or taste bad, and medicines can affect appetite.

Food availability may be affected if elders are unable to shop, drive, walk or stand for long periods of time. Cooking may be limited if they have problems standing or holding utensils, pots and pans, and so on. Poor appetite or lack 
of appetite may plague elders who live alone, are lonely or do not feel like cooking, while the lack of funds to buy food affects food accessibility, availability, quality and variety.

Finally, low literacy may mean that some elders are unable to read or comprehend nutrition and wellness information. Poor vision can make it difficult to read nutrition labels and to control intakes of dietary sodium, sugar and fat, as well as to avoid foods to which one is sensitive.

\section{Role of socioeconomic factors}

While chronic diseases and illnesses are more prevalent in older adults, poor health is not an inevitable consequence of aging. The annual decline in serious and less-serious chronic illness disability, ranging from $0.7 \%$ to $2.3 \%$ from 1982 to 1999 in a number of national studies, reveals a healthier group of older people than suspected, particularly those over 85 . This decline in chronic illness and disability may be due to better nutrition, lifestyle and health care. This theory suggests that investments in health-care technology and nutrition could preserve human capital in the U.S. economy. (Crimmins et al. 1997; Ljubuncic et al. 2008).

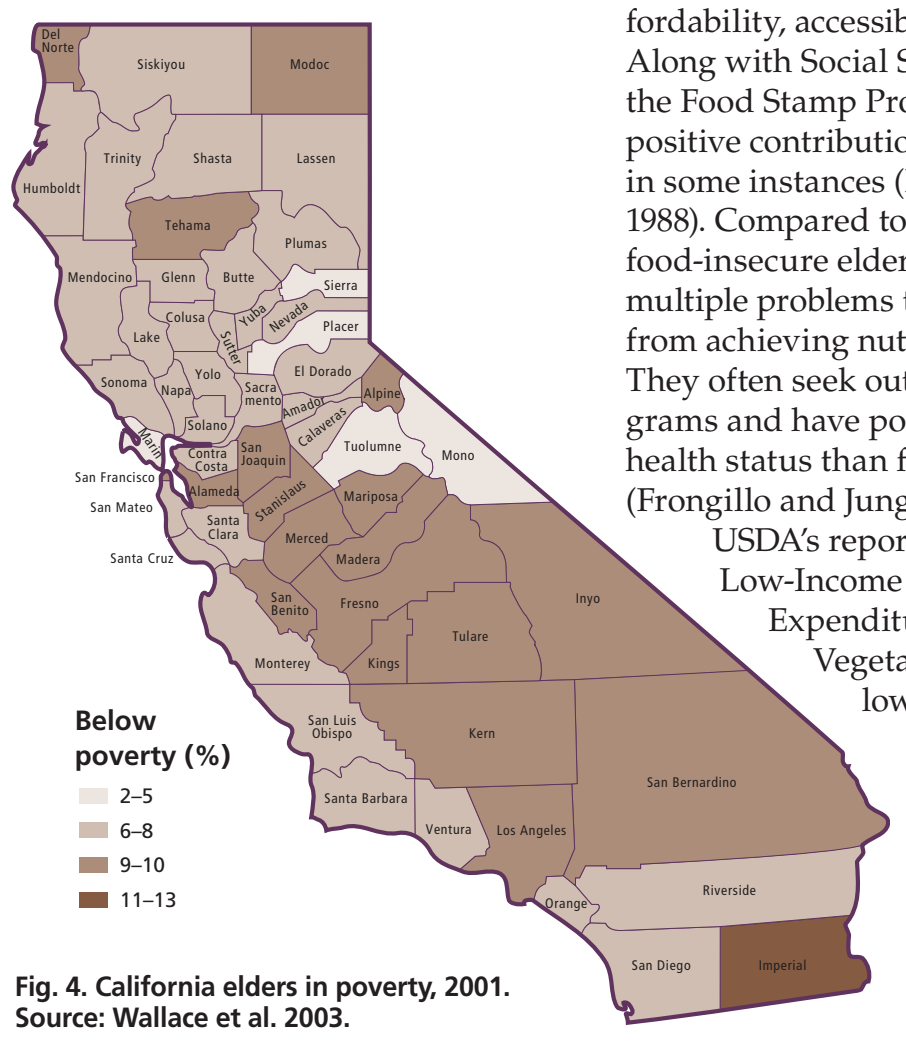

Nonetheless, the diets of many older Americans do not provide the nutrient levels needed to maintain a healthy body (Weimer 1997). To understand functional impacts on the nutrition and health status of the aging population, factors such as education, finances, mobility, general health status, physiological needs, physical exercise and knowledge about nutrition, wellness and disease prevention must be taken into account.

The U.S. Department of Agriculture Economic Research Service (USDA/ ERS) continuing survey 1989-1991 found that education and income were positively related to the nutrient consumption of elderly heads of households. Elders at $130 \%$ of the poverty level tended to have lower nutrient intakes than those with higher incomes (Weimer 1998). In California, more than $28 \%$ of seniors over 65 live at $200 \%$ of the poverty level, and more than $8 \%$ live below the poverty level (fig. 4) (see box).

\section{Food security and limited incomes}

Food security (social and economic access to sufficient, safe and nutritious food that meets dietary needs and food preferences) among the elderly is associated with food availability, affordability, accessibility and utilization. Along with Social Security income, the Food Stamp Program has made positive contributions to nutrient intake in some instances (Hama and Chern 1988). Compared to food-secure elders, food-insecure elders most often present grams and have poorer nutritional and health status than food-secure elders -Income Households' penditures on Fruits and egetables, found that low-income households spent less per capita on these food items than higher income households (Blisard et al. 2004). In this report, Cornell University researchers examined the factors associated with food insecurity among the elderly, their affect on nutritional and health status and the impact of food assistance programs on the needy. They found that low income, education levels, minority status and participation in food assistance programs were significantly related to food insecurity (see box).

\section{USDA/ERS 1989-1991 continuing survey findings}

The USDA Economic Research Service conducts continuing surveys about every 3 years; the 1989-1991 survey assessed changes in dietary behavior. The dietary intake estimates were averages for 15,968 individuals of all ages (excluding breastfed children) who provided at least 1 day of information.

- Highly educated and higher income elders consumed more vitamin $\mathrm{E}$, vitamin $\mathrm{C}$, vitamin B6, niacin, calcium, phosphorus and magnesium.

- Low-income elders consumed significantly fewer calories and eight of 11 nutrients, except vitamin E, calcium and iron.

- Geographically, elders in the U.S. Northeast consumed more calories, fat, vitamin C, vitamin B6, niacin, phosphorous and magnesium.

- Urban elders generally were more deficient in iron than suburban or rural residents.

- Blacks consumed fewer calories, fat, vitamin E, vitamin B6, niacin, calcium, phosphorus, magnesium, iron and zinc than whites; Hispanics consumed more protein than whites.

- Women were more deficient in all nutrients than men, except vitamin $\mathrm{C}$.

- Elders diagnosed with chronic diseases such as diabetes, cancer and heart disease tended to consume significantly less fat.

Source: Frongillo and Jung 1999. 
In addition to food security issues, self-assessments of limited-income seniors $(n=377)$ from 22 senior centers in Alameda County found that literacy was an important consideration in compliance with nutrition- and

\section{Nutrition recommendations for adults over age $\mathbf{5 0}$}

- Achieve adequate nutrition within calorie needs from nutrient-dense foods, and limit saturated and trans fats, cholesterol, added sugars, salt and alcohol.

- Maintain body weight in a healthy range, and lose weight slowly.

- Participate in 30 minutes of moderate physical activities daily to reduce the functional decline of aging.

- Keep fat consumption between $20 \%$ and $35 \%$ of total caloric intake.

- Choose fiber-rich carbohydrates such as fruits, vegetables and whole grains.

- Limit sugar, caloric sweeteners and starch to prevent dental problems.

- Use no more than 2,300 milligrams sodium (1 teaspoon table salt) per day, and eat potassiumrich fruits and vegetables to reach 4,700 milligrams per day total salt.

- Middle-aged and older, hypertensive and black adults should reduce salt intake to $1,500 \mathrm{mil}-$ ligrams per day.

- Limit daily alcoholic beverages to two for men and one for women.

- Do not consume alcohol if it can interact with medications, or when medical conditions prohibit its use.

- To prevent food-borne illness, do not eat unpasteurized, improperly cooked or uncooked foods.

Source: US DHHS 2005a. wellness-related prevention and management plans. Literacy level was a key factor in the participants' belief that they could comply with nutrition and lifestyle changes related to disease prevention and treatment. Many reported that they were confused by the volume and kinds of information they received from either the public, media or healthcare providers (see pages 189, 195).

\section{Promoting improved quality of life}

Quality of life includes physical and mental well-being as well as overall satisfaction and engagement with life; examples include close relationships with family members, active participation in religion or politics, and other relationships with the world (Wallace 2005). Interventions to promote quality of life are more effective if they can be integrated into a person's normal activities, such as easily available, low-cost fresh fruits and vegetables, or safe parks where people can exercise (IOM 2005). Good nutrition can help to improve the quality of life of older Americans by preventing malnutrition or dietary deficiencies, and promoting optimal body functioning (see box).

Reluctance to develop health promotion programs targeting independentliving older people has stemmed from the preconceived notion that individual seniors will not follow plans or change their lifestyle. However, not all seniors are stuck in their old ways (Amarantos et al. 2001). Chernoff (2001) studied reductions in salt and fat intake among older people and found that behavioral changes were associated with the belief that a healthier diet would contribute to better health. A survey of men and women 51 years and older found that trying to follow a healthful diet was the most consistent reason given for the use of vitamin and mineral supplements (Sebastian et al. 2007). Higher levels of some nutrients were also associated with supplements (Archer et al. 2005).

The Food Marketing Institute's 2006 Shopping for Health Survey found an increased interest in health and nutrition across all age groups (Gorman 2007). However, some high-risk, olderadult audiences are still not being reached with messages about the relationship between nutrition and wellness, and quality of life.

Knowler et al. (2002) suggested that lack of profit motive may hamper the effective promotion of lifestyle changes to achieve improved states of wellness. For example, promoting exercise would improve the health of seniors, but companies are not likely to profit if older adults decide to walk around their neighborhoods each morning.

\section{Future prospects}

If the goal of healthy aging is to add life to years, rather than years to life, then nutrition plays an important role - along with activity to enhance physical strength, stability, mobility, feelings of wellness and independence. Research by UC faculty and specialists has contributed significantly to basic knowledge of the aging process and the roles of selected nutrients. The University

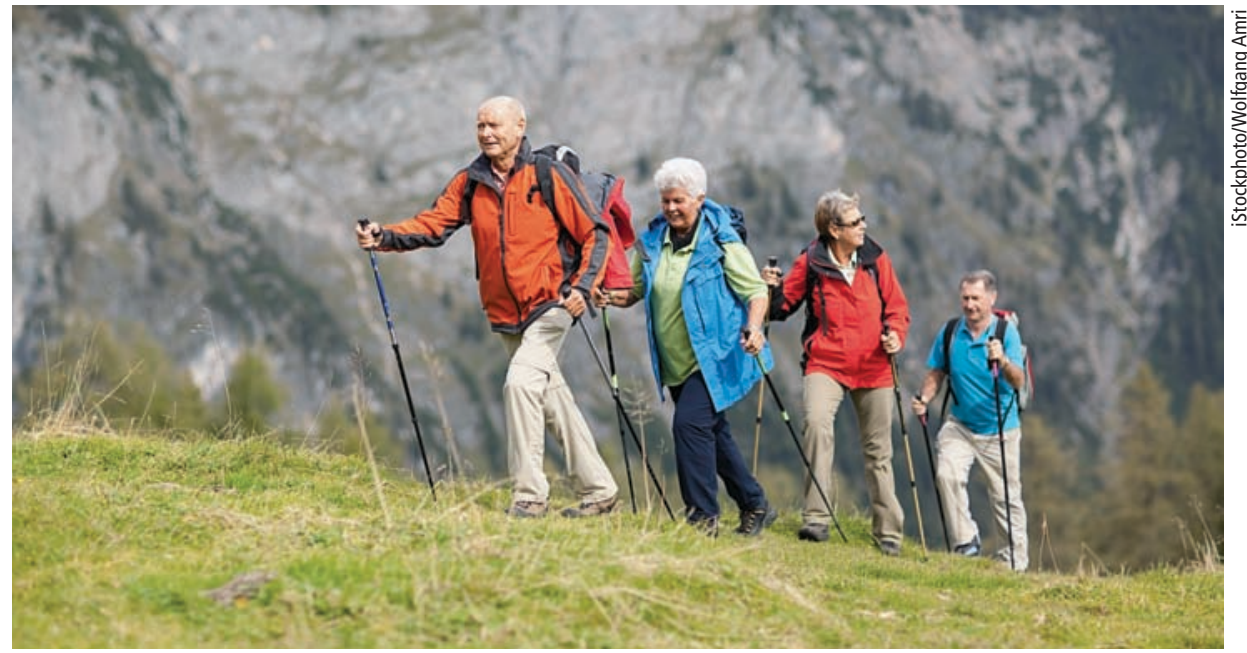

Physical activity enhances strength, stability, mobility, and overall wellness and independence, but public health messages touting its benefits rarely target seniors. 


\section{The goal of healthy aging is to add life to years, rather than years to life.}

is in a unique position to lead efforts to change the conditions under which elders live. For example, UCCE could facilitate partnerships among local growers and senior facilities to promote fruit and vegetable consumption. Likewise, local advisors and educators can help to increase nutrition and wellness knowledge in order to change voluntary health behaviors such as diet

\section{References}

Albert SM, Im A, Raveis V. 2002. Public health and the second 50 years of life. Am J Public Health 92:1214-6.

Aldwin CM, Gilmer DF. 2001. Health, IIIness and Optimal Aging: Biological and Psychosocial Perspectives. Thousand Oaks, CA: Sage Pub. 418 p.

Amarantos E, Martinez A, Dwyer J. 2001. Nutrition and quality of life in older adults. J Gerontol Ser A: Bio Sci Med Sci 56(2):54-64.

[AOA] Administration on Aging. 2003. A Profile of Older Americans. US Department of Health and Human Services, Washington, DC. www.aoa.gov/prof/ statistics/profile/2003/3asp.

Archer SL, Stamler J, Moag-Stahlberg A, et al. 2005 Association of dietary supplement use with specific nutrient intakes among middle-aged American men and women: The INTER Map Study. J Am Diet Assoc 105:1106-14.

Blanton CA, Horwitz BA, Murtagh-Mark C, et al. 1998. Meal patterns associated with the age-related decline in food intake in the Fischer 344 rat. Am J Physiol 275:R1494-502.

Blisard N, Stewart H, Jolliffe D. 2004. Low-income households' expenditures on fruits and vegetables. USDA Economic Research Service, Washington, DC www.ers.usda.gov/publications/aer833.

[CDA] California Department of Aging. 2003. Statistics and Demographics: Facts about California's Elderly. Sacramento, CA. www.aging.state.ca.us/html/stats/ demographics.html.

Chernoff R. 2001. Nutrition and health promotion in older adults. J Gerontol A: Biol Sci Med Sci $56(2): 47-53$

Crimmins E, Saito Y, Reynolds S. 1997. Further evidence on recent trends in the prevalence and incidence of disability among older Americans from two sources: The LSOA and the NHIS. J Gerontol: Social SC 52B(1):S59-71.

Damron-Rodriguez J, Frank JC, Enriquez-Haass VL, Reuben DB. 2005. Definitions of health among diverse groups of elders: Implications for health promotion. Generations 29(2):11-6.

Drewnowski A, Evans WJ. 2001. Nutrition, physical activity and quality of life in older adults. J Gerontol Ser A: Biol Sci Med Sci 56(2):89-94.

Economist. 2000. Disability life expectancy. June 10 p 88-9. or physical activity, and promote peer support. A collaborative group of basic and applied researchers, UCCE advisors and educators, and partners in local communities throughout California could develop, test and institute effective strategies for community-based, institutional and societal interventions to enhance healthy aging among Californians.

Ekonomov AL, Rudd CL, Lomakin AJ. 1989. Actuarial aging rate is not constant within the human life span. Gerontology 35(2-3):113-20.

Frongillo EA, Jung SL. 1999. Impact of Food Insecurity and Food Assistance Program Participation on Nutritional Risk among the Elderly. USDA Economic Research Service, Washington, DC.

Gompertz B. 1860. On the nature of the function expressive of the law of human mortality, and on a new mode of determining the value of life contingencies. Philosoph Trans Royal Soc London 115:513-85.

Gorman E. 2007. Healthy eating: Why and how we are changing what we eat. Mercanti Chronicle. August. www.mercantigroup.com.

Hama M, Chern WS. 1988. Food expenditures and nutrient availability in elderly households. J Consum Aff 22:3-19.

Hughes SL, Prohaska TR, Rimmer JH, Heller T. 2005. Promoting physical activity among older people. J Am Soc Aging (summer):54.

[IOM] Institute of Medicine. 2002. The Future of the Public's Health in the 21st Century. Washington, DC: Nat Acad Pr. 536 p.

IOM. 2005. Does the Built Environment Influence Physical Activity? Spec Rep 282. Transportation Research Board. Washington, DC: Nat Acad Pr. 248 p

IOM. 2008. Retooling for an Aging America: Building the Health Care Workforce. Washington, DC. Report Brief (April). $4 \mathrm{p}$.

Kant AK, Graubard BI, Schatzkin A. 2004. Dietary patterns predict mortality in a national cohort: The National Health Interview Surveys, 1987 and 1992. J Nutr 134:1793-9.

Knowler WC, Barrett-Connor E, Fowler SE, et al. 2002 Reduction in the incidence of type 2 diabetes with lifestyle intervention or metiformin. New Engl J Med 346(6):393-403

Lee RD, Carter L. 1992. Modeling and forecasting the time series of U.S. mortality. J Am Stat Assoc 87(Sept):659-71

Ljubuncic P, Globerson A, Reznick AZ. 2008 Evidenced-based roads to the promotion of health in old age. J Nutr Health Aging 12(2):139-43.

Lopez ES. 2002. Census 2000 for California: A Friendly Guide. California Research Bureau. CRB 02-007. Sacramento, CA.
M.L. Blackburn is Nutrition, Family and Consumer Sciences Advisor, UC Cooperative Extension, Alameda County; B. Gillogy is Chair, Gerontology Department, American River College, Sacramento; and P. Hauselt is Assistant Professor of Geography, Department of Anthropology and Geography, California State University, Stanislaus. We acknowledge the UCLA Center for Health Policy Research for the use of their Health of Older Californians data. Funding was provided by the UC ANR Aging Californians in Rural and Urban Settings Workgroup.

Morley J. 2001. Decreased food intakes with aging. J Gerontol Ser A: Biol Sci Med Sci 56(2):81-8.

Pakin YV, Hrisanov SM. 1984. Critical analysis of the applicability of the Gompertz-Makeham Law in human populations. Gerontology 30(1):8-12.

Rowe JW, Kahn RL. 1997. Successful aging. Gerontologist 37(4):433-40.

Saltzman JR, Russell RM. 1998. The aging gut. Nutritional issues. Gastroenterol Clin N Am 27(2):309-24.

Sebastian RS, Cleveland LE, Goldman JD, et al. 2007. Older adults who use vitamin/mineral supplements differ from nonusers in nutrient intake adequacy and dietary attitudes. J Am Diet Assoc 107(8):1322-32.

US Census Bureau. 2001. Census 2000 Summary Files 1 and 3. www.census.gov (accessed 5/12/2008).

US Census Bureau. 2010. State and County Quick Facts. http://quickfacts.census.gov/qfd/states/06000. html.

[US DHHS] US Department of Health and Human Services. 2000. Healthy People 2010. Washington, DC. www.healthypeople.gov.

US DHHS. 2005a. Dietary Guidelines for Americans 2005. Washington, DC. www.health.gov/dietaryguide lines/dga2005/document/default.htm.

US DHHS. 2005b. Eating Well as We Age. FDA Consumer Health Information, Washington, DC. No 05$1107 \mathrm{C}$

Wakimoto P, Block G. 2001. Dietary intake, dietary patterns and changes with age. J Gerontol Ser A: Biol Sci Med Sci 56(2):65-80.

Wallace S. 2005. The public health perspective on aging. Generations 29(2):5-10.

Wallace SP, Pourat N, Enriquez-Haass V, Sripipatana A 2003. Health of Older Californians: County Data Book. UCLA Center for Health Policy Research, Los Angeles, CA. 133 p.

Weimer JP. 1997. Many elderly at nutritional risk. USDA Economic Research Service, Food and Consumer Economics Division. Food Rev (Jan-Apr):42-8.

Weimer JP. 1998. Factors affecting nutrient intake of the elderly. In: The Economics of Food, Farming, Natural Resources, and Rural America. No AER769, October. USDA Economic Research Service, Washington, DC. 20 p.

Williams GC. 1957. Pleiotropy, natural selection and the evolution of senescence. Evolution 11:398-411. 